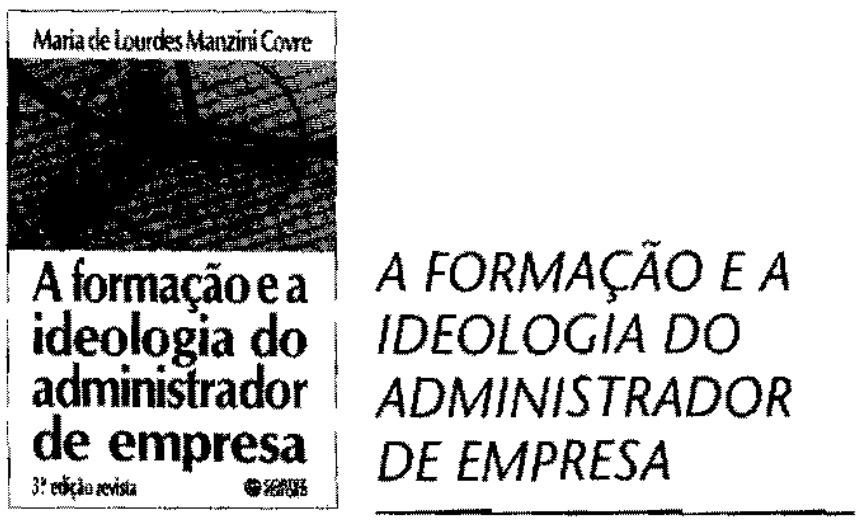

de MARIA DE LOURDES MANZINI COVRE

$3^{\text {a }}$ ed. São Paulo: Cortez Editora, 1990.

por Maria Ester de Freitas, Professora Assistente do Departamento de Administraçäo Geral e Recursos Humanos da EAESP/FGV.

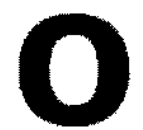

livro da Professora Covre é uma marca das discussôes que estiveram presentes nos meios acadêmicos dos anos 70 e inicio de 80 , onde näo apenas a formaçăo do profissional de Administração, mas a própria Teoria Geral da Administração era questionada a respeito do seu viés ideológico.

Esta terceira edição não acrescenta muito à primeira, publicada em 1981 pela Editora Vozes. O corpo do trabalho se mantém inalterado e traz toda uma fundamentaçẵo teórica sobre a Ideologia Neocapitalista e o processo de burocratização. Esse referencial, traçado nos primeiros capítulos, é utilizado na análise de uma pesquisa empírica, realizada em 1976, junto aos alunos do curso de graduação - diurno e noturno - e do CEAG (Curso de Especialização ern Administração para Graduados), da EAESP/FGV.

Inicialmente a autora se dedica a um debate sobre a ideologia neocapitalista, onde são apresentadas idéias de Max Weber, H. Jacob, J. Burnham, Crozier, Galbraith, Paulantzas, W. Mills, P. Sewezy, Marx e outros.

Ao utilizar o termo ideologia, a autora se vale tanto do conceito marxista, isto é, como "forma de consciência social", quanto do sentido dado por Gramsci de "cimento, que une toda estrutura social e permeia todas as relaçöes sociais". A ideologia neocapitalista significa não uma nova ideologia, mas a ideologia burguesa adaptada à etapa monopolista do capital, onde a razão técnica e um corpo gerencial especializado atuam tanto nas empresas privadas quanto no Estado.

No Brasil, a ideologia neocapitalista assume o caráter de "ideologia desenvolvimentista", cuja formaçäo tem seus antecedentes históricos nos governos Vargas e Kubitschek. O primeiro numa versão de "projeto autônomo" e calcado na substituiçăo de importaçōes; o segundo, como um caminho para um Brasil "moderno", via uma industrialização engajada ao capital estrangeiro.
As Escolas de Administração tề a sua criação no Governo Vargas, sendo a FGV criada em 1944, a EBAP - Escola Brasileira de Administração Pública em 1952 e a EAESP - Escola de Administraçăo de Empresas de São Paulo em 1954. O processo de expansão do ensino superior se dá a partir da reforma educacional de 1968 e o desenho de Universidade considera três pontos fundamentais: a segurança nacional, o vínculo com a comunidade e o ensino adequado às necessidades nacionais. $O$ número de cursos e matriculas em Administraçăo e Economia cresce vertiginosamente no período de $1969 / 1974$.

A EAESP/FGV foi escolhida para a pesquisa desenvolvida pela autora considerando: sua origem, seu prestigio junto ao meio empresarial e o tipo de ensino proporcionado. A clientela-alvo dos cursos da EAESP, seu corpo docente e os resultados da formaçâo săo analisados. A caracterizaçầo dos níveis culturais e sócioeconômicos dos alunos, um corpo docente produtor de teorias e, outras condiçôes, como currículo escolar, produziram um perfil profissional, que a autora chama de "vanguarda". Tal perfil responderia de maneira eficaz às exigências específicas da fase monopolista do capital, que ora se implantava.

Ainda que os dados levantados espelhem uma realidade de 1976 e que a dinâmica da EAESP tenha produzido uma série de mudanças, como extinção do curso noturno, criação dos cursos de mestrado/doutorado, curso de administraçấo pública, o estudo da Professora Covre se mostra bastante útil para uma melhor reflexão sobre as escolas de administração brasileiras.

No que diz respeito à EAESP, o livro não é apenas uma análise histórica, mas a confírmação de uma identidade. Solidamente construída, cuja imagem de "vanguarda" se mantém atualmente nas suas iniciativas de internacionalizaçăo, tendência a um perfil mais generalista, criação de um MBA - Master in Business Administration, maior estreitamento de relaçōes com o meio empresarial e governamental etc.

Um ponto questionável do trabalho da Professora Covre diz respeito à amostra estudada. Ali incluem-se: alunos de pós-graduação plenamente inseridos no mercado de trabalho, alunos de graduação em fase de estágio e alunos apenas alunos. As opiniôes e expectativas de cada segmento são diferenciadas e influenciadas pelo status do momento, portanto, de difícil generalização. Nesse sentido, a tipologia apresentada pela autora peca pela dificuldade de se estabelecer fronteiras entre, por exemplo: "administrador em ascensão", "administrador propriamente dito", "administrador tecnocrata ou de vanguarda", e ainda: "administrador desajustado", "deslocado" "marginal".

O postácio, acrescentado na terceira edição, traz o resultado de uma pesquisa realizada na PUC/SP em 1986, porêm o mesmo não permite maiores comparações com o tipo "vanguarda" da EAESP, seja pelos momentos his- 
tóricos diferentes (de repressão e abertura democrática), seja pela insuficiência dos dados expostos.

Essas ressalvas, contudo, em nada desmerecem o trabalho da autora, que proporcionará - sem dúvida um alimento estimulante para a reflexão sobre o tipo de ensino, o tipo de compromisso que educadores e escolas de administração devem ter: estamos formando apenas um detentor de emprego ou aspiramos a mais? e o que é esse mais? Embora a pesquisa seja datada, a análise crítica desenvolvida provoca uma reflexão que deve fazer parte do dia-a-dia do profissional de ensino: com que tipo de educação estamos comprometidos? Por esta razão, a obra é de importância especial para professores, bem como alunos dos cursos de pós-graduação em administração, educação e sociologia.

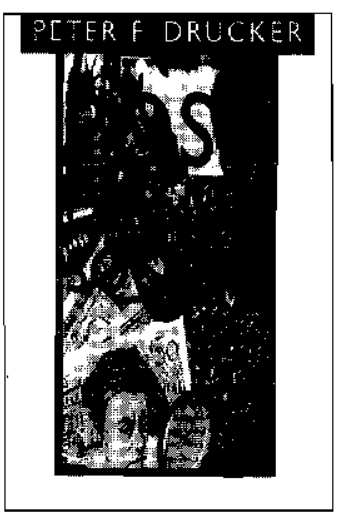

\section{POST CAPITALIST SOCIETY}

\section{de PETER F. DRUCKER}

Oxford: Butterworth-Heinemann, 1993, 204p.

por Carlos Osmar Bertero, Professor do Departamento de Administraçāo Geral e Recursos Humanos da EAESP/FGV.

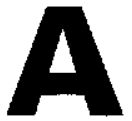

os que esperam mais um texto do decano dos gurus da administração está reservada uma surpresa. $O$ livro fala de administração, mas não no seu primeiro plano, nem como sua principal preocupação. O livro está dividido em três partes; Sociedade, Política e Conhecimento, dimensões centrais do que Drucker considera a sociedade pós-capitalista, designação provisória para a sociedade e para o momento que vivemos. Drucker não se alinha com os triunfalistas, que ao constatarem o fim do comunismo se rejubilam com a vitória do capitalismo, do qual temos exemplo recente em Fukuyama com o seu Fim da História. Acredita que as mesmas forças históricas que sepultaram o comunismo sepultaram também o capitalismo, pelo menos como classicamente definido a partir dos economistas e filósofos sociais do século passado. Lembra que o sistema econômico dos EUA dificilmente poderia ser chamado de capitalismo. A revolução dos Managers, estudada minuciosamente por Alfred K. Chandler e prenunciada na década de trinta por Berle e Means e que retirou dos acionistas a gestão efetiva das empresas, é hoje sucedida pelo fim dos acionistas. Quase $60 \%$ das açōes de sociedades anônimas norteamericanas são hoje propriedade de fundos de pensão.

Neste contexto, Drucker nos aconselha a pensar rapidamente sobre as alteraçōes que estão ocorrendo e mesmo sobre aquelas que já ocorreram, a fim de evitar que continuemos a tentar entender a realidade através de teorias que já foram arquivadas pelos fatos e pela história.

Se a sociedade capitalista e a ensaiada alternativa comunista tinham na propriedade privada, ou na sua eliminação, um elemento fundamental e legitimador, a nova sociedade, chamada de pós- capitalista, talvez por falta de melhor nome, tem no conhecimento seu ponto focal. É no fundo uma sociedade do conhecimento e isso acaba alterando tanto o mundo das organizações como o da sociedade global, incluindo a poítica e especialmente o estado.

As organizações capitalistas eram grandes análogos mecânicos voltados à produção em massa, onde o uso da autoridade e da hierarquia asseguravam o controle e a coordenação. $O$ modelo básico da organização capitalista foi o militar, delineado no século XVIII pelo exército prussiano. A organização moderna não se apóia em pessoas com poucas ou nenhuma qualificação, que, sob estreita supervisão, realizam eficientemente suas tarefas após período relativamente curto de treinamento. $\mathrm{O}$ que está no centro da organização pós-capitalista é a capacitação sob forma de conhecimento. Se a sociedade capitalista foi a do operário, a pós é a do Knowledge Worker ou seja, do conhecedor. Aqui conseqüentemente o tradicional formato organizacional hierarquizado e controlador perdeu funcionalidade e o que temos é um trabalhador com elevada capacitação e uma produtividade derivada do conhecimento e não mais do uso da força física (manpower) para movimentar coisas e alterar matérias-primas. Se o modelo capitalista era a organização militar, o modelo pós é provavelmente o da orquestra sinfônica, onde cada membro da organização, um capacitado especialista, que conhece perfeitamente o seu instrumento e a partitura, toca, sem nenhuma intermediação hierárquica, para o próprio maestro. Talvez a empresa pós-capitalista seja aquela onde todos tendem a se reportar ao presidente. Isto leva também a alteração da estrutura ocupacional da sociedade pós-capitalista, onde os que trabalham com rotinas, com pouca qualificação, como os tradicionais operários, tenderá a perder importância, seja como parcela da população economicamente ativa, seja em termos de renda. Os que são "conhecedores" (Knowledge Workers) tendem a adquirir importância e aumentar sua participação na renda nacional e a ascender sócio-economicamente. Estas tendências criam certos problemas para as sociedades 